\title{
Southeastern European
}

National Cancer Institute

\section{Source}

National Cancer Institute. Southeastern European. NCI Thesaurus. Code C153344.

Denotes a person whose ancestry is in any of the European countries of the Balkan peninsula: T urkey, Albania, Bosnia and Herzegovina, Bulgaria, Republic of Macedonia, Romania, Serbia, Greece, Croatia, Moldova and Montenegro. 